\title{
An analytical model for the current voltage characteristics of GaN-capped AlGaN/GaN and AlInN/GaN HEMTs including thermal and self-heating effects
}

\author{
A. Bellakhdar ${ }^{1}$, A. Telia ${ }^{2}$, and J.-L. Coutaz ${ }^{3}$ \\ ${ }^{1,2}$ Laboratoire des Microsystèmes et Instrumentation, Département d'Electronique, Faculté de Technologie, \\ Université des Frères Mentouri, 2 Campus Ahmed Hamani, Ain El Bey, Constantine, Algeria \\ ${ }^{3}$ IMEP-LAHC, University Savoie Mont Blanc, 73376 Le Bourget du Lac cedex, France
}

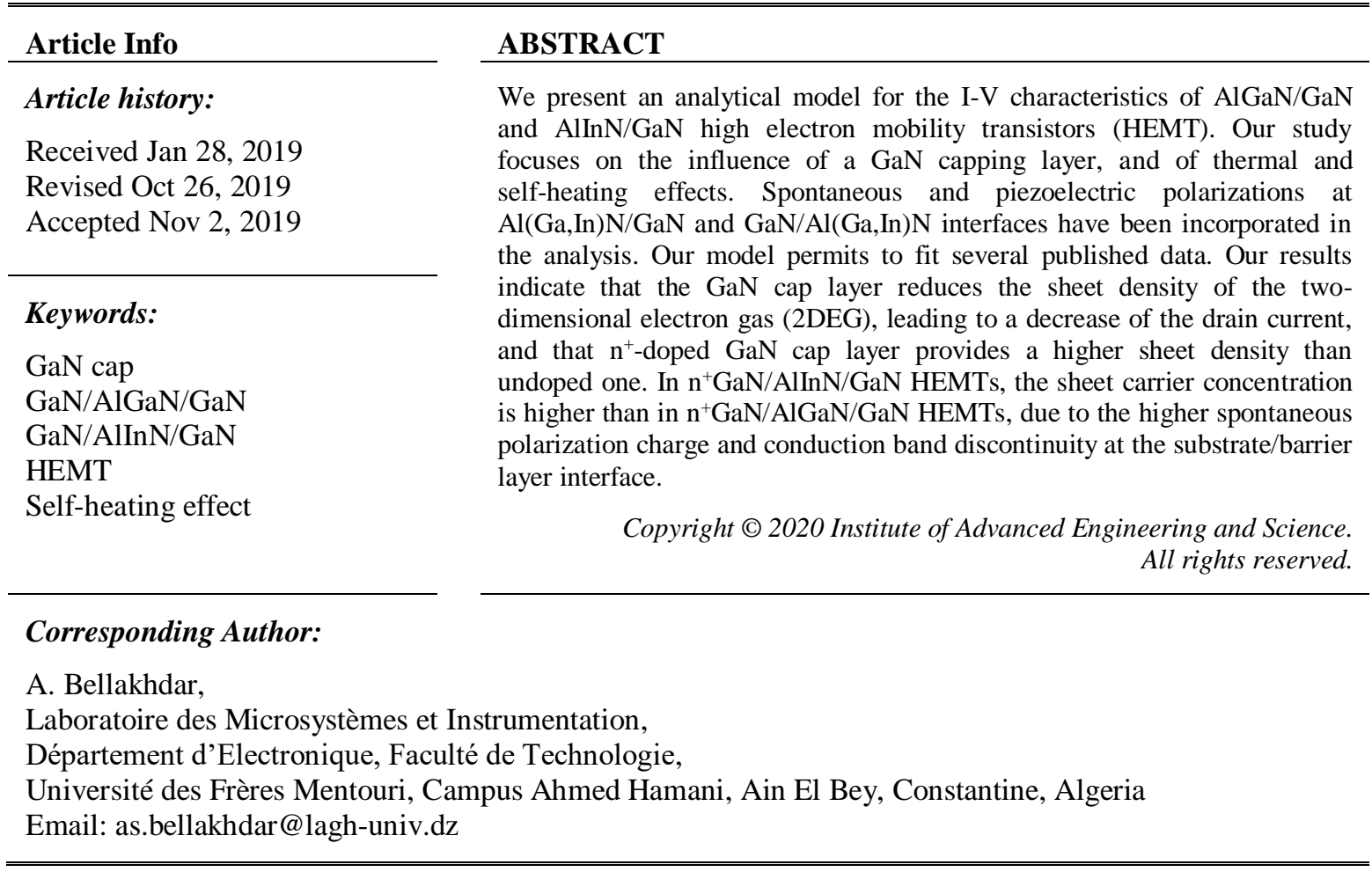

\section{INTRODUCTION}

High electron mobility transistors (HEMTs), based on III-nitrides wide bandgap semiconductors like AlGaN/GaN and AlInN/GaN, are extremely promising devices for high temperature, high power and high speed applications at microwave frequencies, owing to their properties of wide energy bandgap, high saturation electron drift velocity, large conduction band discontinuity and high thermal stability [1, 2]. The lattice mismatch between the $\mathrm{Al}(\mathrm{Ga}, \mathrm{In}) \mathrm{N}$ and $\mathrm{GaN}$ layers produces strong spontaneous and strain-induced piezoelectric polarization field that leads to a large conduction band bending at the heterojunction interface. This creates a high sheet carrier concentration, above $10^{13} \mathrm{~cm}^{-2}$, at the interface without intentional doping, compared with other III-V compound semiconductor-based devices [3, 4]. On the other hand, all devices suffer from the self-heating effect, as the junction temperature in $\mathrm{Al}(\mathrm{Ga}, \mathrm{In}) \mathrm{N}$ HEMTs is very high under high drain voltage, and the drain current is badly reduced. As a consequence, HEMTs performance is greatly degraded by the self-heating and thermal effects $[5,6]$. However, AlInN can be grown lattice-matched to $\mathrm{GaN}$ at a high $\mathrm{Al}$ content of about 83\% (indium content=17\%) [7]. In the lattice-matched $\mathrm{Al}_{0.83} \mathrm{In}_{0.17} \mathrm{~N} / \mathrm{GaN}$ heterostructure, there is no mechanical constraint in the epitaxial structures, which reduces strain-defects related relaxation problems. Moreover, higher sheet carrier density can be induced by the large spontaneous polarization even without piezoelectric polarization, and these transistors show superior performance compared to the conventional AlGaN/GaN HEMTs [8, 9]. 
Recently, a heavily doped n-GaN cap layer has been employed to improve high-frequency performance and to reduce access and ohmic contact resistances. The beneficial effect of cap layers was demonstrated experimentally by Gessmann et al. [10] for $\mathrm{In}_{0.27} \mathrm{Ga}_{0.73} \mathrm{~N} / \mathrm{GaN}$ and $\mathrm{GaN} / \mathrm{Al}_{0.2} \mathrm{Ga}_{0.8} \mathrm{~N}$ structures. Heikman et al. [11] and Asgari et al. [12] have proposed a $\mathrm{GaN} / \mathrm{Al}_{0.32} \mathrm{Ga}_{0.68} \mathrm{~N} / \mathrm{GaN}$ heterostructure deposited on a sapphire substrate, and they show that the sheet carrier density decreases with thicker cap layers while the mobility increases. Similar effects were reported by Tao et al. [13] for an AlN/GaN heterostructure. To maximize the high frequency performance of AlGaN HEMTs, Green et al. [14] incorporated GaN cap layers in $\mathrm{GaN} / \mathrm{AlGaN} / \mathrm{GaN}$ structures by heavily n-doping the upper GaN layer; thus parasitic contact resistances were greatly reduced. Also, the GaN cap layers were shown to be more effective in protecting the samples of $\mathrm{AlGaN} / \mathrm{GaN}$ HEMTs structures from degradation, compared to in-situ grown $\mathrm{Si}_{3} \mathrm{~N}_{4}$ cap layers [15]. The ohmic contact performance on GaN capped AlGaN/AlN/GaN HEMTs was improved by Wang et al. [16] by optimizing the $\mathrm{Ti} / \mathrm{Al} / \mathrm{Mo} / \mathrm{Au}$ electrodes. Finally, activated $\mathrm{p}-\mathrm{GaN}$ cap layers have been demonstrated to increase the breakdown characteristics and reduce the leakage current of $\mathrm{AlGaN} / \mathrm{GaN}$ HEMTs [17].

In this paper, we present an analytical model for the I-V characteristics of these HEMTs with a doped n-GaN cap layer. This study is based on well-established models for the description of the involved phenomena (like polarization-induced sheet charge densities, self-heating effect, drain conductance and so on). Therefore the originality of our work is related to a rather complete modeling of the devices based on classical analytical expressions. As compared to using CAD tools, here the advantage arises from getting analytical expressions, which allow one to enlighten the role of each parameter and to optimize them. We study $\mathrm{n}^{+}-\mathrm{GaN} / \mathrm{AlGaN} / \mathrm{GaN}$ and $\mathrm{n}^{+}-\mathrm{GaN} / \mathrm{AlInN} / \mathrm{GaN}$ structures and we investigate the effect of the $\mathrm{GaN}$ cap layer on threshold voltage, sheet carrier density, current voltage characteristics and drain conductance. Thus our study will allow us to compare AlGaN and AlInN devices with similar structures, as well as the effect of doping the cap layer. The model takes into account the influence of thermal effect over a wide temperature range (300-475 K) and the self-heating effect on the I-V characteristics. Spontaneous and piezoelectric polarization-induced charges have also been considered. Our modeling is validated by comparison with published experimental data.

\section{MODEL FORMULATION}

\subsection{Description of the studied structure}

The studied structures are $\mathrm{GaN} / \mathrm{Al}_{0.32} \mathrm{Ga}_{0.68} \mathrm{~N} / \mathrm{GaN}$ (noted structure A) and $\mathrm{GaN} / \mathrm{Al}_{0.83} \mathrm{In}_{0.17} \mathrm{~N} / \mathrm{GaN}$ (structure B) as depicted in Figure1. They are grown on an undoped GaN thick buffer layer deposited over a $\mathrm{SiC}, \mathrm{Si}$ or sapphire substrate. The 2DEG channel appears at the interface between the buffer layer and the undoped $\mathrm{Al}_{0.32} \mathrm{Ga}_{0.68} \mathrm{~N}$ or $\mathrm{Al}_{0.83} \mathrm{In}_{0.17} \mathrm{~N}$ spacer layer. An n-doped $\mathrm{AlGaN}(\mathrm{AlInN})$ thick barrier layer provides the 2DEG sheet charge density. It is covered by a second undoped additional layer, and then by the thin $\mathrm{GaN}$ cap layer. This last one could be undoped or heavily $\mathrm{n}^{+}$-doped with $\mathrm{Si}$ to a concentration equal to $10^{20} \mathrm{~cm}^{-3}$. The second spacer layer prevents impurity scattering from the $\mathrm{n}^{+}-\mathrm{GaN}$ cap to the $\mathrm{n}-\mathrm{AlGaN}$ (AlInN) layer [18], which increases the density and mobility of carriers in the channel. The thickness of the different layers are specified on Figure 1. The GaN cap layer on top of the hetero-structure raises the conduction band and produces a large enhancement in effective barrier height $E_{\text {beff. }}$ This is due to a negative polarization charge $(-\sigma)$ at the upper hetero-interface, which increases the electric fields in the barrier layer, and hence decreases the 2DEG density, leading to a reduction in the gate leakage current [14].

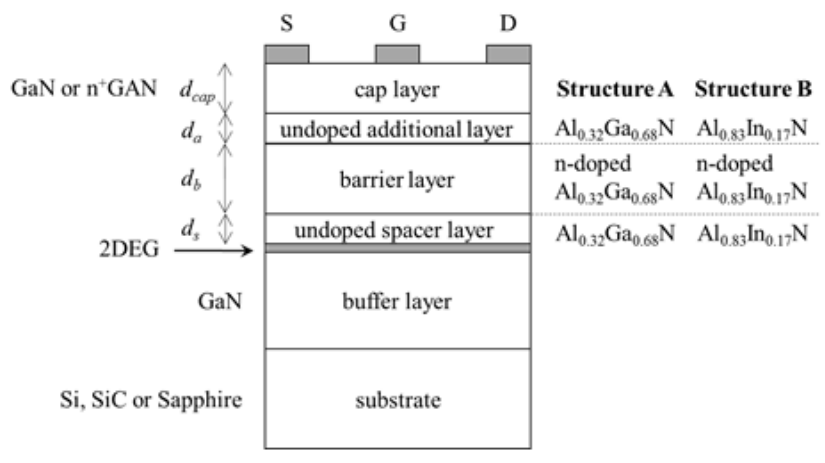

Figure 1. Cross-sectional structure of $\mathrm{GaN} / \mathrm{Al}_{0.32} \mathrm{Ga}_{0.68} \mathrm{~N} / \mathrm{GaN}$ (structure $\mathrm{A}$ ) and $\mathrm{GaN} / \mathrm{Al}_{0.83} \mathrm{In}_{0.17} \mathrm{~N} / \mathrm{GaN}$ (structure B) 
When the GaN cap becomes thicker, the charge density in the channel is smaller; the valence-band $\Delta E_{v}$ of the GaN cap shifts upwards, and the valence band eventually reaches the Fermi level $E_{F}$. At this point, a two-dimensional hole gas (2DHG) is formed at the upper GaN/Al(Ga,In)N interface Figure 2 b-right [11]. The n-doping of the GaN is also advantageous because it reduces the contact resistance [16]. All the main geometrical parameters of the structures are defined and their values are given in Table 1 . The electrical parameters of the structure materials are defined and their values are given in Table 2. Finally, the physical parameters that depend on the $\mathrm{Al}$ mole fraction $m$ are listed in Table 3, in which their expressions versus $m$ is given.

Table 1. Geometrical parameters of the structures used in the simulation.

\begin{tabular}{ccc}
\hline Parameter & Description & Values \\
\hline$L$ & gate length & $1 \mu \mathrm{m}$ \\
$w$ & gate width & $100 \mu \mathrm{m}$ \\
$\Delta d$ & 2 DEG depth in GaN & $10 \mathrm{~nm}$ \\
$d_{s}$ & spacer layer & $3 \mathrm{~nm}$ \\
$d_{a}$ & additional layer & $3 \mathrm{~nm}$ \\
$d_{b}$ & barrier layer & $20 \mathrm{~nm}$ \\
$d_{c a p}$ & GaN cap layer & $1,3,5 \mathrm{~nm}$ \\
\hline
\end{tabular}

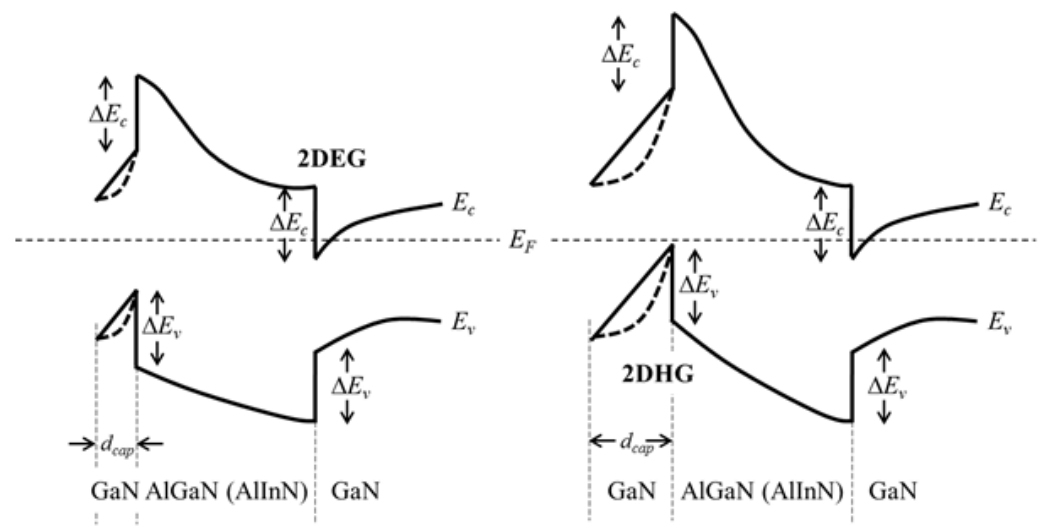

Figure 2. HEMT heterostructures with a thin (left) or thick (right) GaN capping layer

Table 2. Electrical parameters of the structures used in the simulation

\begin{tabular}{lll}
\hline Parameter & Description & Values \\
\hline$E_{c}$ & critical electric field & $190 \times 10^{5} \mathrm{~V} / \mathrm{m}$ \\
$v_{\text {sat }}$ & saturation velocity & $2.1 \times 10^{5} \mathrm{~m} / \mathrm{s}$ \\
$\mu_{o}$ & low field mobility & $9 \times 10^{-2} \mathrm{~cm}^{2} / \mathrm{V} / \mathrm{s}$ \\
$R_{s}$ & parasitic source resistance & $0.3 \Omega$ \\
$R_{d}$ & parasitic drain resistance & $0.3 \Omega$ \\
$N_{d}$ & barrier doping concentration & $1 \times 10^{18} \mathrm{~cm}^{-3}$ \\
$N_{\text {cap }}$ & n+GaN cap doping density & $1 \times 10^{20} \mathrm{~cm}^{-3}$ \\
$R_{t h}$ & thermal resistance & $6 \mathrm{~K} / \mathrm{W}$ \\
\hline
\end{tabular}

Table 3. Material parameters used in the calculation [19-22]

\begin{tabular}{llllc}
\hline Parameter & \multicolumn{1}{c}{ Description } & Expression for $\mathrm{Al}_{\mathrm{m}} \mathrm{Ga}_{(1-\mathrm{m})} \mathrm{N}$ & \multicolumn{1}{c}{ Expression for $\mathrm{Al}_{\mathrm{m}} \operatorname{In}_{(1-\mathrm{m})} \mathrm{N}$} & $\mathrm{Units}$ \\
\hline$\varepsilon_{2}(m)$ & dielectric constant & $(-0.5 m+9.5) \times 8.854 \times 10^{-12}$ & $(-4.3 m+14.21) \times 8.854 \times 10^{-12}$ & $\mathrm{C} / \mathrm{m} / \mathrm{V}$ \\
$\Phi(m)$ & Ni Schottky barrier & $1.3 m+0.84$ & $1.94 m+0.2$ & $\mathrm{eV}$ \\
$C_{13}(m)$ & elastic constant & $5 m+103$ & $24 m+70$ & $\mathrm{GPa}$ \\
$C_{33}(m)$ & elastic constant & $-32 m+405$ & $172 m+205$ & $\mathrm{GPa}$ \\
$a(m)$ & lattice constant & $(-0.077 m+3.189) \times 10^{-10}$ & $(-0.4753 m+3.5848) \times 10^{-10}$ & $\mathrm{~m}$ \\
$e_{31}(m)$ & piezoelectric constant & $-0.11 m-0.49$ & $-0.12 m-0.21$ & $\mathrm{Cm}^{-2}$ \\
$e_{33}(m)$ & piezoelectric constant & $0.73 m+0.73$ & $0.69 m+0.81$ & $\mathrm{Cm}^{-2}$ \\
$P^{S P}(m)$ & spontaneous polarization & $-0.052 m-0.029$ & $-0.048 m-0.042$ & $\mathrm{Cm}^{-2}$ \\
$E_{g}(m)$ & energy band gap & $6.13 m+3.42(1-m)-m(1-m)$ & $6.28 m+0.7(1-m)-3.1 m(1-m)$ & $\mathrm{eV}$ \\
$\Delta E_{c}(m)$ & band discontinuity & $0.7 \times\left(E_{g}(m)-E_{g}(0)\right)$ & $0.63 \times\left(E_{g}(m)-E_{g}(0)\right)$ & $\mathrm{eV}$ \\
\hline
\end{tabular}




\subsection{Threshold voltage}

The threshold voltage $V_{t h}$ is defined as the applied gate voltage for which the channel is completely depleted, and is considered as the minimum potential in the channel [23]. The dependence of $V_{t h}$ on temperature and $\mathrm{Al}$ mole fraction $m(m=0.32$ for structure $\mathrm{A}$, and $m=0.83$ for $\mathrm{B})$, including the effects of both spontaneous and piezoelectric charge polarization, is given by the following expressions: without cap [24]:

$$
V_{t h}(m)=-q \frac{N_{d} d_{b}}{\varepsilon_{2}(m)}\left(d_{a}+\frac{d_{b}}{2}\right)+\frac{E_{S c h o t t k y}}{q}-\frac{\Delta E_{C}(T, m)}{q}-\frac{\sigma^{+}(m) d_{1}}{\varepsilon_{2}(m)}
$$

where $d_{1}=d_{s}+d_{a}+d_{b}+\Delta d$.

$$
V_{t h}(m)=-\frac{q N_{c a p} d_{c a p}^{2}}{2 \varepsilon_{1}}-\frac{q N_{d} d_{b}}{\varepsilon_{2}(m)}\left(d_{a}+\frac{d_{b}}{2}+\frac{\varepsilon_{2}(m)}{\varepsilon_{1}} d_{c a p}\right)+\frac{E_{S c h o t t k y}}{q}+\frac{E_{F}}{q}-\frac{\sigma^{-}(m) d_{c a p}}{\varepsilon_{1}}-\frac{\sigma^{+}(m) d}{\varepsilon_{2}(m)}
$$

where $d=d_{1}+\frac{\varepsilon_{2}(m)}{\varepsilon_{1}} d_{c a p}$.

$d_{1}$ is the distance between the gate and the channel without GaN cap layer, $q$ is the electronic charge, $E_{\text {Schottky }}$ represents the Schottky barrier height between the metal and the $\mathrm{Al}(\mathrm{Ga}, \mathrm{In}) \mathrm{N}$ layer in bare structures and between the metal and $\mathrm{GaN}$ in caped structures, $\varepsilon_{2}(m)$ and $\varepsilon_{1}$ are the dielectric constants of respectively $\mathrm{Al}_{\mathrm{m}}(\mathrm{Ga}, \mathrm{In})_{1-\mathrm{m}} \mathrm{N}$ and $\mathrm{GaN}, E_{F}$ is the Fermi level assuming $\Delta E_{F}=0$ at $300 \mathrm{~K}[19]$, and $\sigma$ is the polarization-induced charge density at the interface see Figure 3. If $\sigma$ is positive, free electrons will tend to compensate for the polarization-induced charge and will form a 2DEG. On the other hand, a negative sheet charge density causes an accumulation of holes, leading to a 2DHG at the interface [25]. In our simulation, we use a Ni Schottky barrier contact at the surface.

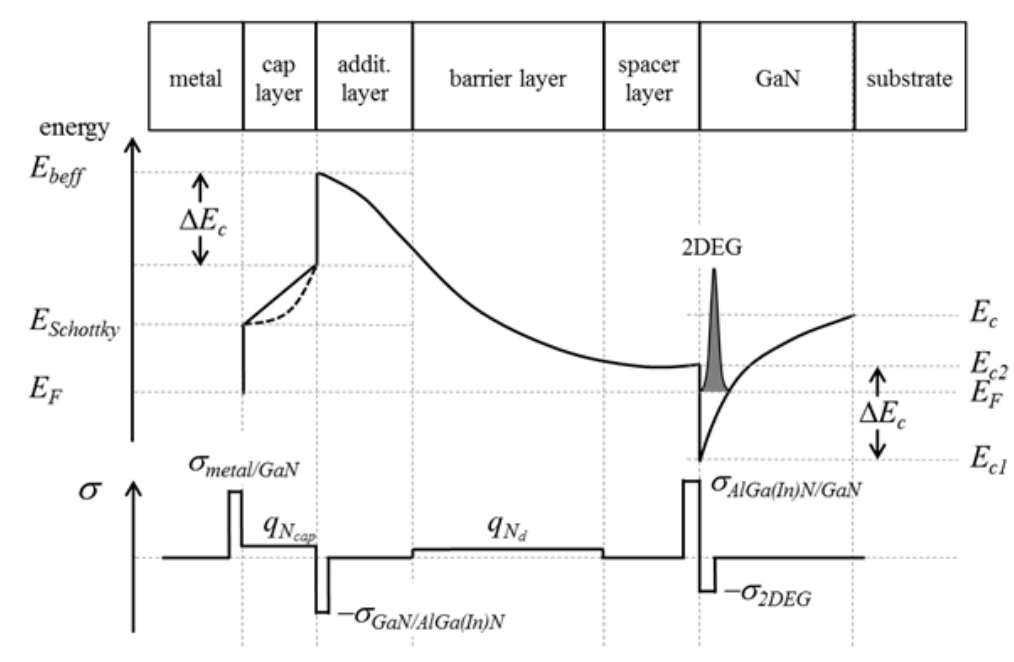

Figure 3. Conduction band energy profile of the structures (the dashed line corresponds to the doped GaN cap, while the continuous line is for the undoped case) and charge distribution profile

\subsection{Charge control model}

The sheet carrier density $n_{s}$ is one of the principal entities governing the performance and operation of $\mathrm{Al}(\mathrm{Ga}, \mathrm{In}) \mathrm{N} / \mathrm{GaN}$ HEMT devices [26]. When a gate voltage $V_{g s}$ is applied through a Schottky contact, the sheet carrier density $n_{s}$, under strong inversion region in the channel formed at the $\mathrm{AlGa}(\mathrm{In}) \mathrm{N} / \mathrm{GaN}$ interface, is obtained from self-consistent 1-D Poisson's and Schrodinger's equations in the quantum well, assuming a triangular potential profile [27], and considering spontaneous and piezoelectric polarizations [28, 29] as: 


$$
n_{S}(x, T, m)=\frac{2 q D \varepsilon_{2}(m)}{\varepsilon_{2}(m)+2 q^{2} D d} \times\left(V_{g s}-V_{t h}(T, m)-V_{c}(x)\right), \quad \text { with } d=\frac{d_{c a p} \varepsilon_{2}(m)}{\varepsilon_{1}}+d_{1}, D=\frac{4 \pi m^{*}}{h^{2}} .
$$

Here $d$ is the density of state in the conduction band of the 2DEG system, $m^{*}$ is the electron effective mass, $V_{c}(x)$ is the channel potential at any point $x$ along the channel due to the applied drain voltage, $V_{g s}$ is the gate-to-source bias voltage.

\subsection{Polarization-induced sheet charge density}

The direction of the polarization-induced field formed at the upper $\mathrm{GaN} / \mathrm{Al}(\mathrm{Ga}, \mathrm{In}) \mathrm{N}$ interface $(-\sigma)$ is opposite to that in the lower $\mathrm{Al}(\mathrm{Ga}, \mathrm{In}) \mathrm{N} / \mathrm{GaN}$ one $(+\sigma)$ Figures 3 and 4. Then, the conduction band is rising as shown in Figure 3. Therefore 2DEG and 2DHG appear at the $\mathrm{Al}(\mathrm{Ga}, \mathrm{In}) \mathrm{N} / \mathrm{GaN}$ and GaN/Al(Ga,In)N interfaces respectively, as shown in Figure 4.

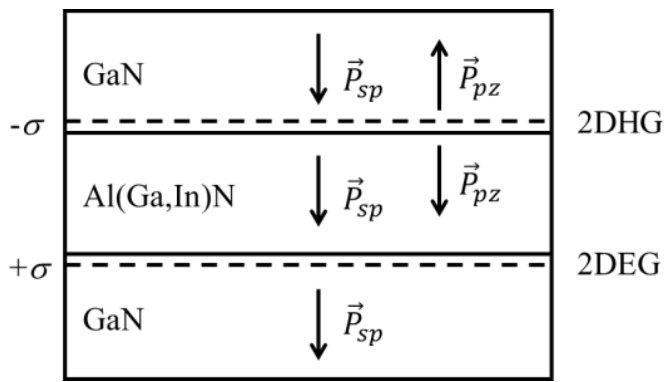

Figure 4. Polarization -induced sheet charge density and direction of the spontaneous and piezoelectric polarizations in $\mathrm{GaN} / \mathrm{Al}(\mathrm{Ga}, \mathrm{In}) \mathrm{N}$ and $\mathrm{Al}(\mathrm{Ga}, \mathrm{In}) / \mathrm{GaN}$

The total polarization $P$ is the sum of the piezoelectric $P^{P Z}$ and spontaneous $P^{S P}$ polarizations, which induce a sheet charge density $\sigma$ at the hetero-interfaces [19]:

$$
P_{A l_{m}(G a, I n)_{1-m} N}=P_{A l_{m}(G a, I n)_{1-m} N}^{P Z}+P_{A l_{m}(G a, I n)_{1-m} N}^{S P}
$$

At the lower interface of the heterostructures, the total polarization can change abruptly, which creates a fixed polarization charge $\sigma$ defined by:

$$
\sigma^{+}(m)=\sigma_{A l_{m}(G a, I n)_{1-m} N / G a N}=P_{G a N}-P_{A l_{m}(G a, I n)_{1-m} N}=\left(P_{G a N}^{S P}+P_{G a N}^{P Z}\right)-\left(P_{A l_{m}}^{S P}(G a, I n)_{1-m} N_{A l_{m}(G a, I n)_{1-m} N}\right) .
$$

Similarly, at the upper interface of the hetero-structure, the charge density is:

$$
\sigma^{-}(m)_{G a N / A l_{m}(G a, I n)_{(1-m)} N}=-\sigma^{+}(m)_{A l_{m}(G a, I n)_{(1-m)} N / G a N}
$$

Thus the net polarization induced sheet charge density at $\mathrm{Al}(\mathrm{Ga}, \mathrm{In}) \mathrm{N} / \mathrm{GaN}$ interface is given by:

$$
\sigma(m)=\left|P_{A l_{m}(G a, I n)_{1-m} N}^{P Z}+P_{A l_{m}(G a, I n)_{1-m} N}^{S P}-P_{G a N}^{S P}\right|
$$

The piezoelectric polarization-induced charge density is:

$$
{ }_{A}^{P Z} P l_{m}(G a, I n)_{1-m} N=2 \frac{a(0)-a(m)}{a(m)}\left[e_{31}(m)-e_{33}(m) \frac{C_{31}(m)}{C_{33}(m)}\right] .
$$

\subsection{Current-voltage characteristics}

The drain source current in the 2-DEG channel can be expressed from the current density equation presented in [27], where temperature effects are included in the electron mobility and channel charge density terms: 


$$
I_{d s}(T, m, x)=w q \mu(T, x)\left(n_{s}(T, m, x) \frac{d V_{C}(x)}{d x}+\frac{k_{B} T}{q} \frac{\partial n_{s}(T, m, x)}{\partial x}\right)
$$

where $k_{B}$ is the Boltzmann constant and $\mu(T, x)$ is the temperature dependent mobility, whose expression is given in [30-31]:

$$
\mu(T, x)=\frac{\mu_{O}(T)}{1+\frac{1}{E_{1}} \frac{d V_{C}(x)}{d x}}, \quad \text { with } E_{1}=\frac{E_{c} v_{s a t}}{\mu_{O}(T) E_{c}-v_{s a t}} .
$$

Substituting expressions (3) and (10) in (9), and integrating along the channel leads to [30]:

$$
I_{d s}(T, m)=\frac{-A_{2}+\sqrt{A_{2}^{2}-4 A_{1} A_{3}}}{2 A_{1}},
$$

with:

$$
\left\{\begin{array}{l}
A_{1}=\left(\frac{\mu_{0} E_{c}-v_{s a t}}{E_{c} v_{s a t}}-\frac{w \mu_{0} q^{2} D \varepsilon_{2}(m) R_{d}}{\varepsilon_{2}(m)+2 q^{2} D d}\right)\left(R_{d}+2 R_{S}\right), \\
A_{2}=\frac{2 w \mu_{0} q^{2} D \varepsilon_{2}(m)}{\varepsilon_{2}(m)+2 q^{2} D d} \times\left(V_{d s}\left(R_{S}+R_{d}\right)-V_{g s}^{\prime}\left(2 R_{S}+R_{d}\right)\right)-L-\frac{\mu_{0} E_{C}-v_{s a t}}{E_{c} v_{s a t}} V_{d s}, \text { and } V_{g s}^{\prime}(m)=V_{g s}-V_{t h}(T, m)-\frac{k_{B} T}{q} . \\
A_{3}=\frac{2 w \mu_{0} q^{2} D \varepsilon_{2}(m)}{\varepsilon_{2}(m)+2 q^{2} D d} \times V_{d s}\left(V_{g s}^{\prime}-\frac{V_{d s}}{2}\right),
\end{array}\right.
$$

$V_{d s}$ is the drain-to-source voltage. For the sake of simplicity, the dependence on $T$ and/or $m$ of the coefficients $A_{i}, \mu_{0}$ and $\varepsilon$ has not be written down in the preceding expressions and will not be from now on. The low-field mobility $\mu_{0}$ depends on the electron concentration $n_{s}(T, m)$, which further depends on the doping concentration, on the temperature and on the material quality. The Caughey-Thomas empirical expression gives the electron concentration [31]:

$$
\mu_{i}(N, T)=\mu_{\max , i}\left(T_{O}\right) \frac{B_{i}(N) \times\left(T / T_{O}\right)^{\beta_{i}}}{1+B_{i}(N)\left(T / T_{O}\right)^{\alpha_{i}+\beta_{i}}}, \quad \text { with } B_{i}(N)=\left[\frac{\mu_{\min , i}+\mu_{\max , i}\left(N_{g, i} / N\right)^{\gamma}}{\mu_{\max , i}-\mu_{\min , i}}\right]_{T=T_{0}} .
$$

Here $i=n$ for electrons and $p$ for holes, respectively, $N$ is the doping concentration, and $T_{o}=300 \mathrm{~K}$. The parameters $\mu_{\max , i}, \boldsymbol{\mu}_{\min , i}, N_{g, i}, \gamma_{i}, \alpha_{i}$ and $\beta_{i}$ are taken from [32] see Table 4.

Table 4. Parameter values for low-field electron mobility [32]

\begin{tabular}{cccccc}
\hline $\begin{array}{c}\mu_{\max , i} \\
\mathrm{~cm}^{2} / \mathrm{V} / \mathrm{s}\end{array}$ & $\begin{array}{c}\mu_{\min , i} \\
\mathrm{~cm}^{2} / \mathrm{V} / \mathrm{s}\end{array}$ & $\begin{array}{c}N_{g, i} \\
\mathrm{~cm}^{-3}\end{array}$ & $\gamma$ & $\alpha$ & $\beta$ \\
\hline 1000 & 55 & $2.10^{17}$ & 1.0 & 2.0 & 0.7 \\
\hline
\end{tabular}

\subsection{Drain conductance}

The drain conductance is an important microwave parameter that determines the maximum voltage gain delivered by the device. The drain conductance of the HEMT is evaluated as [24]:

$$
g_{d}(T, m)=\left.\frac{\partial I_{d s}(T, m)}{\partial V_{d s}}\right|_{V_{g s}}=\frac{\left(A_{2}-\sqrt{A_{2}^{2}-4 A_{1} A_{3}}\right) \frac{\partial A_{2}}{\partial V_{d s}}-2 A_{1} \frac{\partial A_{3}}{\partial V_{d s}}}{2 A_{1} \sqrt{A_{2}^{2}-4 A_{1} A_{3}}}
$$

with: $\begin{cases}\frac{\partial A_{1}}{\partial V_{d s}}=0, & \frac{\partial A_{2}}{\partial V_{d s}}=A\left(R_{S}+R_{d}\right)-\left(\frac{\mu_{0} E_{C}-v_{s a t}}{E_{C} v_{s a t}}\right), \\ \frac{\partial A_{3}}{\partial V_{d s}}=A\left(V_{g s}^{\prime}-V_{d s}\right), & A=\frac{2 w \mu_{0} q^{2} D \varepsilon}{\left(\varepsilon+2 q^{2} D(d)\right)} .\end{cases}$ 


\subsection{Incorporation of self-heating effect (SHE)}

Self-heating is one of the critical factors that adversely affects device performance and reliability in high-power and high temperature applications. The temperature increase caused by self-heating reduces the performance of the devices and enhance their degradation. In reality, the self-heating effect (SHE) corresponds to an increase of the crystal temperature due to a high power dissipation in the active zone of AlGaN/GaN HEMT transistors operating at large biases. This enhances the phonon scattering rate, which reduces the mobility and the electron saturation velocity [5]. Consequently, this results in a negative slope of drain current versus drain voltage. Modeling SHE has been address in a few studies, which consider the effect of self-heating and hot electrons on polarization-induced charges and the defect-induced traps at all the device interfaces [28, 33]. We include here a simple model of SHE [34], in which the temperature increase results from the dissipation of the power $P_{\text {diss }}$ in a phenomenological thermal resistance $R_{t h}$ :

$$
\Delta T=P_{d i s s} R_{t h}
$$

Thus, the actual working temperature $T$ of the devices is corrected by adding $\Delta T$ to the ambient temperature $T_{0}$ :

$$
T=T_{0}+\Delta T \text {. }
$$

\section{RESULTS AND ANALYSIS s}

\subsection{Electrical performance of the HEMTs without self-heating effects}

Figure 5 shows the influence of the barrier thickness on the sheet carrier density. For structure A, the sheet density increases rapidly for barriers thinner than $10 \mathrm{~nm}$ and then tends to saturate. A similar behavior is observed for structure $\mathrm{B}$, but with a higher saturation value $\left(30 \times 10^{12}\right.$ instead of $15 \times 10^{12} \mathrm{~cm}^{-2}$ around $40 \mathrm{~nm}$ ). Our model is in excellent agreement with experimental data circles in Figure 5 extracted from the literature [11] and [7].

The sheet carrier density is plotted in Figure 6 as a function of the GaN cap layer thickness. The sheet carrier density decreases monotonously when the cap layer becomes thicker and remains almost constant for thick cap layers $\left(\sim 3.8 \times 10^{12} \mathrm{~cm}^{-2}\right.$ for structure A, and $\sim 5.2 \times 10^{12} \mathrm{~cm}^{-2}$ for structure B, over 250 $\mathrm{nm}$ ). Our model permits to fit well the experimental data published in [11]. Figure 7 shows that both structures with an undoped $\mathrm{GaN}$ cap layer exhibit a smaller sheet density than with an $\mathrm{n}^{+}$-doped GaN cap layer. The reduction of $2 \mathrm{DEG}$ sheet density may be attributed to the additional negative polarization charges formed at the interface between $\mathrm{GaN}$ and $\mathrm{Al}(\mathrm{Ga}, \mathrm{In}) \mathrm{N}$. The sheet carrier density increases slightly with the barrier thickness. On the other hand, the 2DEG sheet density is much higher in structure B than in structure A. This improvement is attributed to a better electron confinement in the channel due to a larger electric field, arising firstly from higher spontaneous polarization charge at the $\mathrm{GaN} / \mathrm{Al}_{0.83} \mathrm{In}_{0.17} \mathrm{~N} / \mathrm{GaN}$ hetero interface, and secondly from the conduction band discontinuity formed at the same interface, which is higher than with $\mathrm{GaN} / \mathrm{Al}_{0.30} \mathrm{Ga}_{0.70} \mathrm{~N} / \mathrm{GaN}$. In this latter case, our model fits very well with experimental data of reference [35].

Figure 8 shows the variation of the 2DEG sheet density as a function of the barrier thickness for both structures, for different thicknesses $d_{\text {cap }}$ of undoped (Fig. 8a) and $\mathrm{n}^{+}$-doped Figure. 8b GaN cap layers. Let us notice that the variation of 2DEG sheet density for various values $d_{c a p}$ is significant, especially for undoped GaN cap. The 2DEG sheet density decreases when the undoped GaN cap layer becomes thicker for both structures A and B. This is explained by both the contribution of the heavily doping cap layers in the case of higher thicknesses and by the large spontaneous polarization charge at the $\mathrm{GaN} / \mathrm{Al}_{0.83} \mathrm{In}_{0.17} \mathrm{~N} / \mathrm{GaN}$ hetero interface (structure B).

The variation of threshold voltage $V_{t h}$ as a function of barrier thickness is shown in Figure 9. $V_{t h}$ decreases to more negative values for thicker barrier thicknesses, especially for structure B. Figure 9a shows that the effect of undoped GaN cap is less pronounced than with an $\mathrm{n}^{+}$-doped GaN cap. Our model is in good agreement with experimental data open circles in Figure 9a extracted from [4]. Also $V_{t h}$ decreases to more negative values when the $\mathrm{n}^{+}$-doped $\mathrm{GaN}$ cap layer becomes thicker Figure $9 \mathrm{~b}$.

The variation of the sheet carrier density $n_{s}$ as a function of gate source voltage $V_{g s}$ is presented in Figure 10 for different thicknesses of the $\mathrm{n}^{+}$-doped GaN cap layer. $n_{s}$ increases almost linearly with $V_{g s}$ over a given threshold. Consequently, the depth of the potential well at hetero interface decreases, as well as the 2DEG density [34]. Moreover, the curves shift to more negative $V_{g s}$ when increasing the ${ }^{+}$-doped GaN cap layer thickness, which indicates a simultaneous decrease of the threshold voltage $V_{t h}$. Here again, our model permits to fit experimental data extracted from [35]. 


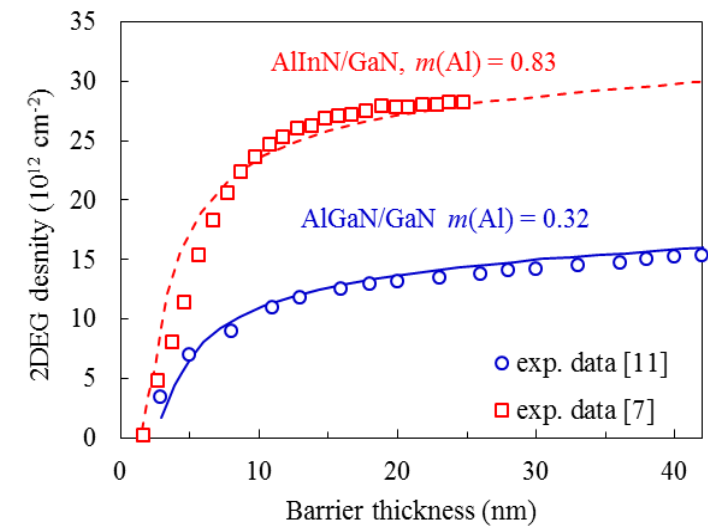

Figure 5. 2DEG sheet density as a function of barrier thickness for structure $\mathrm{A}\left(\mathrm{Al}_{0.32} \mathrm{Ga}_{0.68} \mathrm{~N} / \mathrm{GaN}\right)$ and structure $\mathrm{B}\left(\mathrm{Al}_{0.83} \mathrm{In}_{0.17} \mathrm{~N} / \mathrm{GaN}\right)$. Continuous blue and dashed red lines: our calculation; open blue circles and red squares: experimental data from $[7,11]$

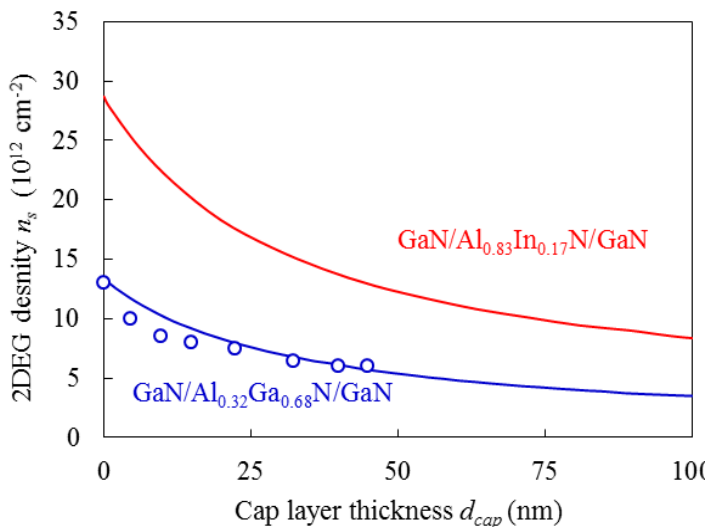

Figure 6. 2DEG sheet density for $\mathrm{GaN} / \mathrm{Al}_{0.32} \mathrm{Ga}_{0.68} \mathrm{~N} / \mathrm{GaN}$ (continuous blue line) and $\mathrm{GaN} / \mathrm{Al}_{0.83} \mathrm{In}_{0.17} \mathrm{~N} / \mathrm{GaN}$ (continuous red line) HEMTs as a function of the GaN capping layer thickness.

Full blue circles are experimental data extracted from [11]

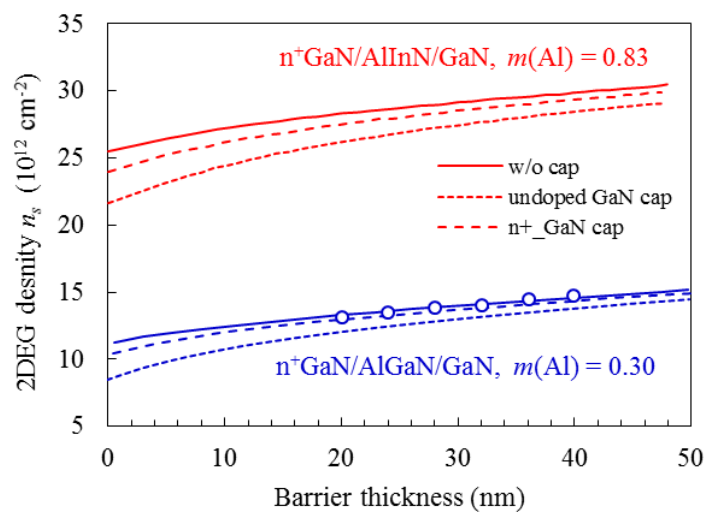

Figure 7. Variation of 2DEG density as a function of barrier thickness for the two structures, without (continuous line), and with undoped (dotted) and $\mathrm{n}^{+}$-doped (dashed) GaN cap layer. Open circles are experimental data extracted from [36]

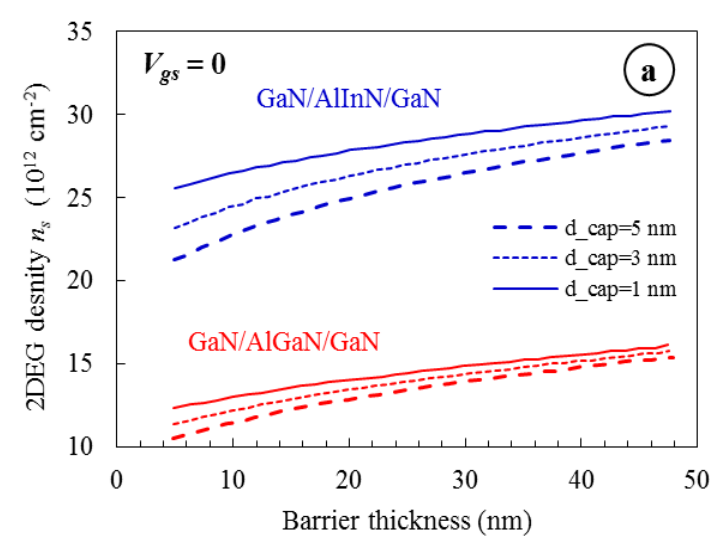

(a)

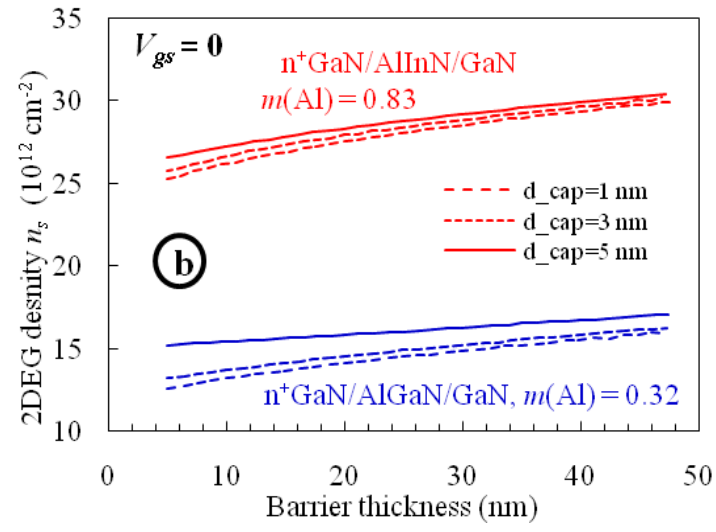

(b)

Figure 8. Variation of 2DEG sheet density as a function of barrier thickness for

the GaN/Al $l_{0.32} \mathrm{Ga}_{0.68} \mathrm{~N} / \mathrm{GaN}$ (structure $\mathrm{A}$ ) and $\mathrm{GaN} / \mathrm{Al}_{0.83} \mathrm{In}_{0.17} \mathrm{~N} / \mathrm{GaN}$ (structure $\mathrm{B}$ ) heterostructures with various values of (a) undoped and (b) $\mathrm{n}^{+}$-doped $\mathrm{GaN}$ cap layer thickness. Here $V_{g s}=0 \mathrm{~V}$ 


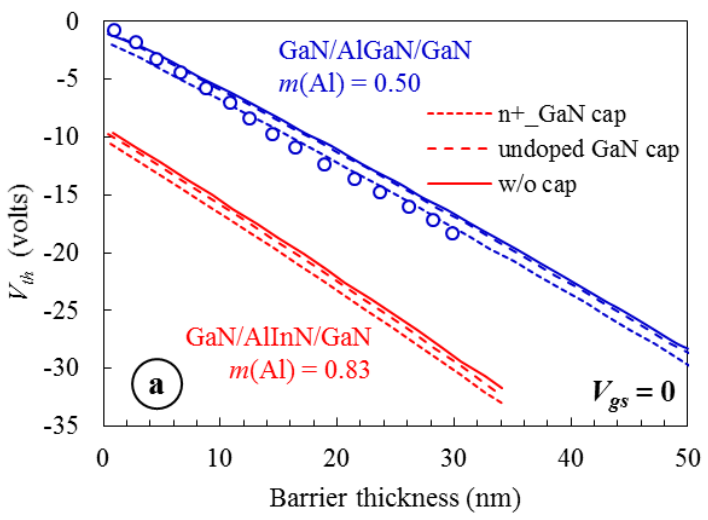

(a)

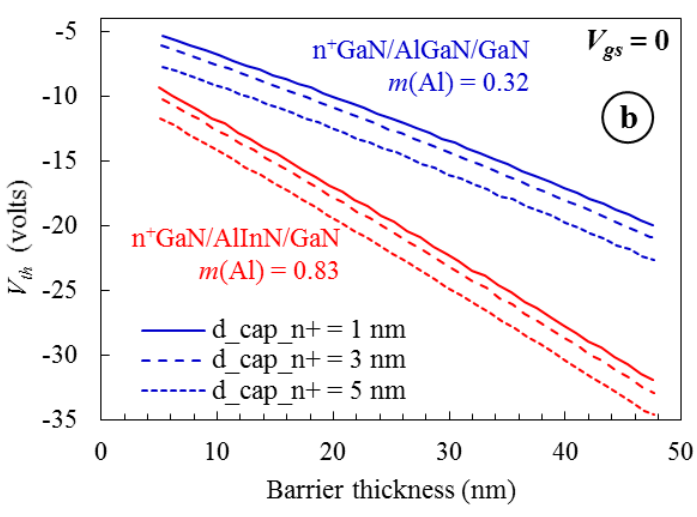

(b)

Figure 9. Variation of threshold voltage as a function of barrier thickness for structures A and B: (a) with undoped, $\mathrm{n}^{+}$-doped and without $\mathrm{GaN}$ cap (the cap thickness is $3 \mathrm{~nm}$ )-open circles are experimental data extracted from [4]; (b) with different thickness values of the $\mathrm{n}^{+}$-doped $\mathrm{GaN}$ cap layer

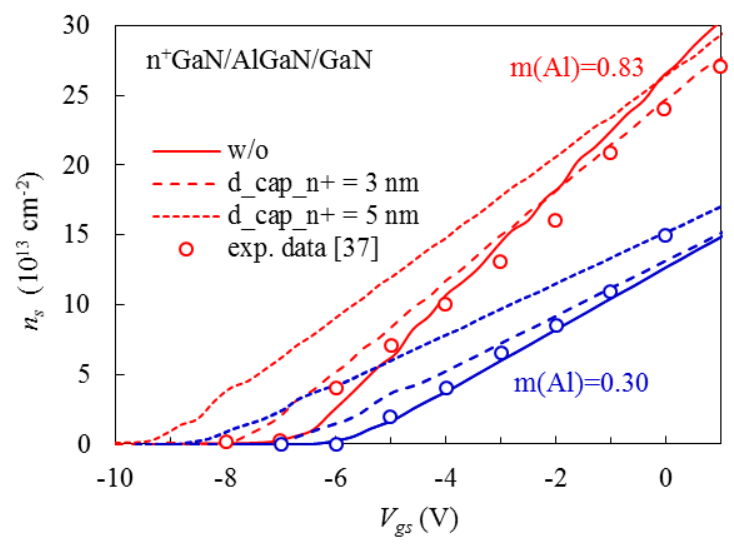

Figure 10. Sheet carrier density versus gate source voltage for different $\mathrm{n}^{+}$-doped GaN cap layer thicknesses and without $\mathrm{GaN}$ cap layer for structure $\mathrm{A}(\mathrm{GaN} / \mathrm{AlGaN} / \mathrm{GaN})$ and different $\mathrm{Al}$ concentrations. Open circles are measured data extracted from [35]

The variation of sheet carrier density $n_{s}$ is plotted in Figure 11 versus the cap layer doping density $N_{\text {cap }}$. As expected, it increases proportionally to $N_{\text {cap }}$. Moreover, the variation is stronger when increasing the cap thickness.Typically, with a 5-nm cap thickness, $n_{s}$ in structure B is almost doubled: $1.28 \times 10^{13} \mathrm{~cm}^{-2}$ $\left(N_{\text {cap }}=0\right)$ to $2.11 \times 10^{13}\left(N_{\text {cap }}=2.75 \times 10^{20} \mathrm{~cm}^{-2}\right)$. This improvement is explained by the additional contribution of heavily doping cap layer of higher thickness and large spontaneous polarization charge in structure $\mathrm{B}$.

As already anticipated from the preceding results, $V_{t h}$ decreases to more negative values when increasing either $N_{\text {cap }}$ or the GaN cap layer thickness Figure 12. For example in structure A, $V_{t h}$ is decreasing from $-10.24 \mathrm{~V}$ without capping layer to $-16.74 \mathrm{~V}$ with $d_{c a p}=5 \mathrm{~nm}$ and $N_{c a p}=2.75 \times 10^{20} \mathrm{~cm}^{-3}$. The drain current is diminished in structures covered with an undoped GaN cap layer, as seen in Figure 13. This can be explained by the reduction of the 2DEG sheet density due to the additional negative polarization charges formed at the interface between $\mathrm{GaN}$ and $\mathrm{Al}(\mathrm{Ga}, \mathrm{In}) \mathrm{N}$. The drain current is more intense in structure $\mathrm{B}$. Also, it is seen that the drain current increases linearly with small values of $V_{d s}$ and then saturates at higher $V_{d s}$ because of the very high sheet charge density, resulting from large conduction band discontinuity and strong polarization effects. Our model is in good agreement with published experimental results [7, 37], even if the doping density $N_{d}$ in the transistors studied in [7] and [37] is different. The effect of the cap layer on the drain source conductance Figure 14 is rather weak. The drain conductance becomes smaller when increasing the drain bias voltage because, as well, the carrier velocity rises gradually and then saturates. 


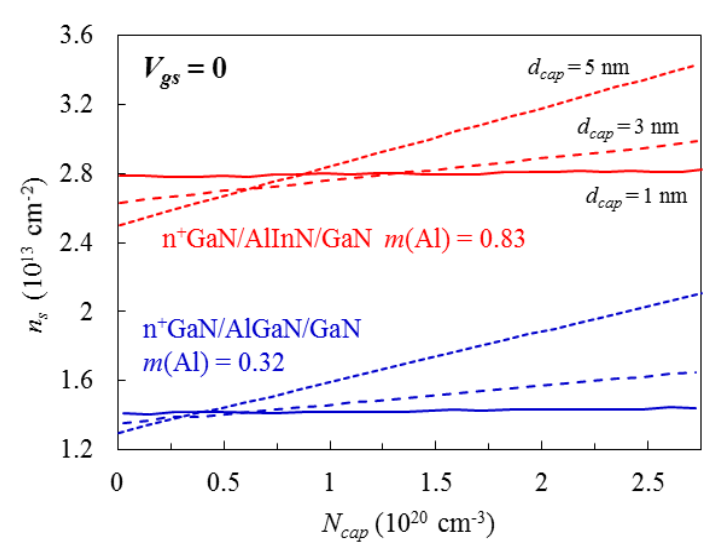

Figure 11. Variation of sheet carrier density as a function of GaN cap doping density with different GaN cap layer thickness for structures A and B

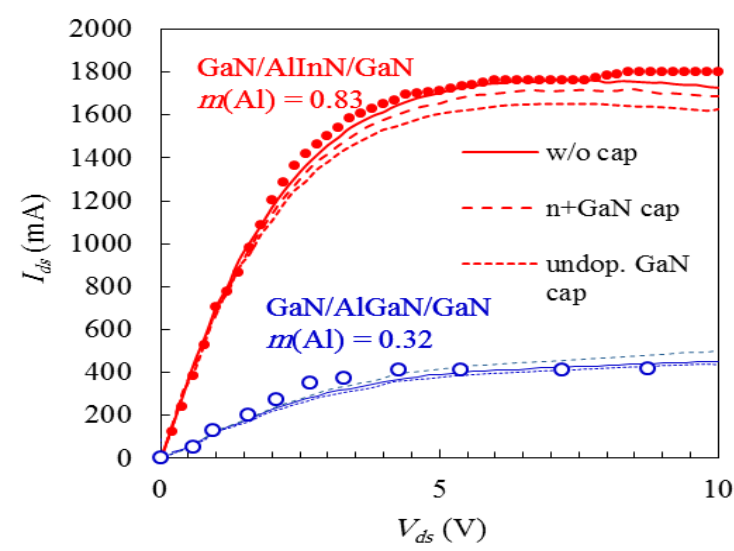

Figure 13. Drain source current vs.drain source voltage for structures $\mathrm{A}\left(N_{d}=5 \times 10^{18} \mathrm{~cm}^{-3}\right.$, $\left.d_{b}=14 \mathrm{~nm}\right)$ and B $\left(N_{d}=4.5 \times 10^{17} \mathrm{~cm}^{-3}\right)$ with undoped, $\mathrm{n}^{+}$-doped and without $\mathrm{GaN}$ cap layer at gate voltage $V_{g s}=0 \mathrm{~V}$. Circles are experimental data extracted from [7] (full circles) and from [38] (open circles)

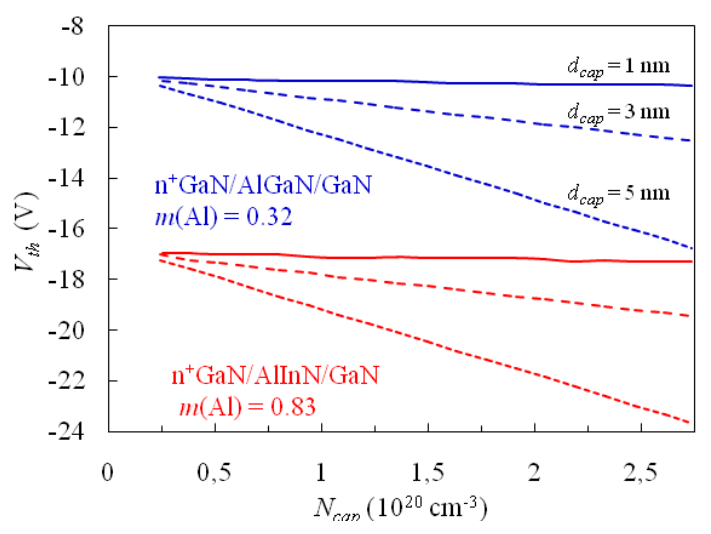

Figure 12. Variation of threshold voltage as a function of GaN cap doping density with different GaN cap layer thicknesses for structures A and B

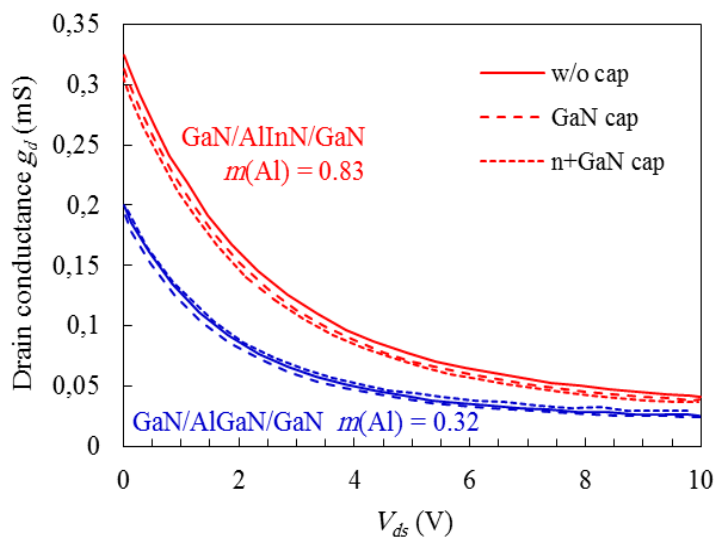

Figure 14. Variation of drain-source conductance as a function of drain-source voltage $V_{d s}$ without and with undoped and $\mathrm{n}^{+}$-doped GaN cap layer. For both structures, the gate voltage is $V_{g s}=0 \mathrm{~V}$

\subsection{Thermal and self-heating effects}

As already explained, thermal and self-heating effects result in a degradation of the HEMTs performance. Figure 15 presents the $I_{d s}-V_{d s}$ curves of both A and B structures, without a cap layer. Each curve is calculated without and with taking into account thermal and self-heating effect, for three different room temperatures, namely $300 \mathrm{~K}$ Figure $15 \mathrm{a}, 375 \mathrm{~K}$ Figure $15 \mathrm{~b}$ and $425 \mathrm{~K}$ Figure $15 \mathrm{c}$. In any case, thermal and self-heating effects decrease strongly the value of the drain-source current. At higher values of the drain voltage, they lead to a negative resistance, which is more important in structure B than in structure A. Increasing the room temperature makes the drain current diminishing, when self-heating is either considered or not for both structures A and B. For example, under a bias $V_{d s}=10 \mathrm{~V}, I_{d s}$ decreases from $\sim 728 \mathrm{~mA}$ at 300 $\mathrm{K}$ to $\sim 663 \mathrm{~mA}$ at $425 \mathrm{~K}$ in structure $\mathrm{B}$. 

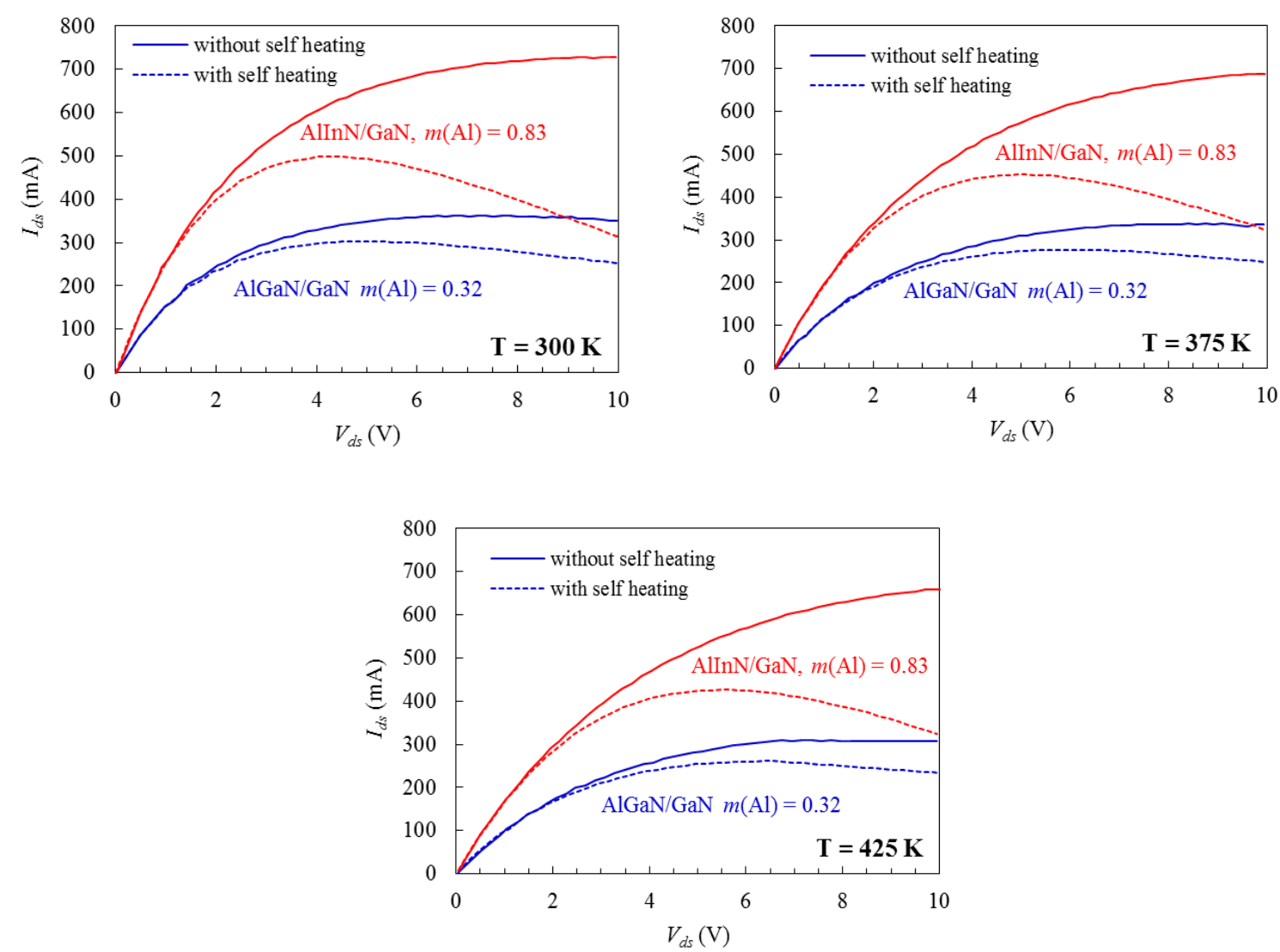

Figure 15. Dependence of drain source current as a function of drain source voltage without GaN cap at $V_{g s}=0 \mathrm{~V}$ including thermal effect and when self-heating is and is not considered for structures A and B.

The temperatures are respectively $T=300,375$, and $425 \mathrm{~K}$

\section{CONCLUSION}

We have presented an analytical model for the current voltage characteristics and drain conductance of $\mathrm{n}^{+} \mathrm{GaN} / \mathrm{Al}(\mathrm{Ga}$,In)N/GaN HEMTs. We have performed a comparative study of the effect of doped and undoped GaN capping layer on the electrical properties of these HEMTs, taking into account thermal and self-heating effects. Our results indicate that the deposition of an undoped GaN cap layer on top of $\mathrm{Al}$ $(\mathrm{Ga}, \mathrm{In}) \mathrm{N} / \mathrm{GaN}$ reduces the electronic sheet density, proportionally to the cap layer thickness, and makes the drain current decreasing. $\mathrm{n}^{+}$-doping the $\mathrm{GaN}$ cap layer leads to similar but more pronounced effects, for example the sheet density becomes higher. Our simulation shows an enhancement of the sheet carrier concentration in $\mathrm{n}^{+} \mathrm{GaN} / \mathrm{AlInN} / \mathrm{GaN}$ structure as compared to the $\mathrm{n}^{+} \mathrm{GaN} / \mathrm{AlGaN} / \mathrm{GaN}$ one. This improvement is attributed to a better electron confinement in the channel due to electric field arising from higher spontaneous polarization charge at the $\mathrm{n}^{+} \mathrm{GaN} / \mathrm{AlInN} / \mathrm{GaN}$ hetero-interface and by a larger conduction band discontinuity formed at the same interface, as compared with $\mathrm{n}^{+} \mathrm{GaN} / \mathrm{AlGaN} / \mathrm{GaN}$. Our analytical model for the $2 \mathrm{DEG}$ density at the $\mathrm{Al}(\mathrm{Ga}, \mathrm{In}) \mathrm{N} / \mathrm{GaN}$ interface is in excellent agreement with experimental data given in the literature [11] and [7].

HEMT's performances are greatly degraded in by self-heating and thermal effects, more in $\mathrm{GaN} / \mathrm{Al}_{0.83} \mathrm{InN}_{0.17} / \mathrm{GaN}$ than in $\mathrm{GaN} / \mathrm{Al}_{0.32} \mathrm{Ga}_{0.68} \mathrm{~N} / \mathrm{GaN}$. The saturated drain current drops significantly when the temperature rises above room temperature from $300 \mathrm{~K}$ to $425 \mathrm{~K}$ in both structures $\mathrm{A}$ and $\mathrm{B}$. Furthermore, the self-heating effect strongly influences the $I_{d s}-V_{d s}$ characteristics. Especially, the drain current at higher drain voltage becomes weaker and a negative resistance effect may arise. In conclusion, $n^{+} \mathrm{GaN} / \mathrm{AlInN} / \mathrm{GaN}$ HEMTs exhibit better performance, especially when covered with a thin highly-doped capping layer, even when self-heating and thermal effects are taken into account. 
APPENDIX: Calculation of $V_{t h}$

We start from the Poisson equation in the doped $n^{+} \mathrm{GaN}$ cap layer:

$$
\begin{aligned}
& \frac{d^{2} V}{d z^{2}}=-\frac{\rho_{c a p}}{\varepsilon_{G a N}}=-\frac{q N_{c a p}}{\varepsilon_{G a N}}, \\
& \Rightarrow \frac{d V}{d z}=-\frac{q N_{c a p}}{\varepsilon_{G a N}} z+k=-E_{5}(z) .
\end{aligned}
$$

$k$ is a constant, $z$ is the height in the structure with origin $(z=0)$ at the 2DEG sheet see Figure 1 . We then write the continuity of at location $z_{3}$ (top of undoped additional layer):

$$
\begin{aligned}
& \varepsilon_{G a N} E_{5}\left(z_{3}\right)=\varepsilon_{A l G a(\operatorname{In}) N}(m) E_{4}\left(z_{3}\right)-\sigma^{-}, \\
& \Rightarrow E_{5}\left(z_{3}\right)=\frac{\varepsilon(m)_{A l G a(I n) N}}{\varepsilon_{G a N}} E_{4}\left(z_{3}\right)-\frac{\sigma^{-}}{\varepsilon_{G a N}} .
\end{aligned}
$$

By comparing (A-2) and (A-4), we obtain:

$$
\begin{aligned}
& k=q \frac{N_{c p}}{\varepsilon_{G a N}} z_{3}-\frac{\varepsilon(m)}{A l G a(I n) N} E_{4}\left(z_{3}\right)+\frac{\sigma^{-}}{\varepsilon_{G a N}}, \\
& \Rightarrow E_{5}(z)=q \frac{N_{c p}}{\varepsilon_{G a N}}\left(z-z_{3}\right)+\frac{\varepsilon(m)}{A l G a(I n) N} E_{4}\left(z_{3}\right)-\frac{\sigma^{-}}{\varepsilon_{G a N}} .
\end{aligned}
$$

We integrate (A-6) from the top of the undoped additional layer to the top of the HEMT:

$$
V\left(z_{4}\right)-V\left(z_{3}\right)=\int_{z_{3}}^{z_{4}} E_{5}(z) d z=\frac{-q N_{c a p}}{2 \varepsilon_{G a N}} d_{c a p}+\left(\frac{\varepsilon_{A l G a(I n) N}}{\varepsilon_{G a N}} E_{4}\left(z_{3}\right)-\frac{\sigma^{-}}{\varepsilon_{G a N}}\right) d_{\text {cap }} .
$$

Then we again apply the continuity of $\vec{D}$ at the top of the undoped additional layer:

$$
\begin{aligned}
& \varepsilon_{G a N} E_{5}\left(z_{3}\right)=\varepsilon(m) A l G a(\operatorname{In}) N \\
& E_{4}\left(z_{3}\right)-\sigma^{-}=\varepsilon(m) \\
& A l G a(\operatorname{In}) N \\
& E_{4}\left(z_{3}\right)=E_{3}\left(z_{2}\right) .
\end{aligned}
$$

These fields can be written from the field in $z=0$ :

$$
E_{4}\left(z_{3}\right)=E_{3}\left(z_{2}\right)=q \frac{-q N_{d} d_{b}}{\varepsilon(m)}+E_{2}(0)
$$

Substituting (A-9) in (A-7) leads to:

$$
V\left(z_{4}\right)-V\left(z_{3}\right)=\frac{-q N_{c a p}}{2 \varepsilon_{G a N}} d_{\text {cap }}^{2}-\frac{q N_{d} d_{b}-\varepsilon_{A l G a(I n) N} E_{2}(0)+\sigma^{-}}{\varepsilon_{G a N}} d_{\text {cap }} .
$$

The effective barrier height $E_{\text {beff }}$ shown in Figure 2 is derived from the energy band diagram:

$$
\begin{aligned}
E_{\text {beff }} & =E_{\text {Schottky }}+\Delta E_{C}+q\left(V\left(z_{4}\right)-V\left(z_{3}\right)\right) \\
& =E_{\text {Schottky }}+\Delta E_{C}-q^{2} \frac{N_{\text {cap }}}{2 \varepsilon_{G a N}} d_{\text {cap }}^{2}-q \frac{q N_{d} d_{b}-\varepsilon_{A l G a}(\text { In }) N}{\varepsilon_{2}(0)+\sigma^{-}} d_{\text {cap }} .
\end{aligned}
$$

$E_{2}(0)$ is the electric field in spacer layer, i.e.:

$$
E_{2}(0)=\frac{V\left(z_{1}\right)-V_{0}}{d_{s}}
$$

Finally, $V_{t h}$ is obtained by entering expressions (A-11) and (A-12) in (A-10) 


\section{REFERENCES}

[1] Y. C. Yao, C. Y. Huang, T. Y. Lin, L. L. Cheng, C. Y. Liu, M. T. Wang, J. M. Hwang, and Y. J. Lee, "Manipulation of polarization effect to engineer III-nitride HEMTs for normally-off operation," Microelectronic Engineering, vol. 138, pp. 1-6, 2015.

[2] O. Kelekci, P. Tasli, S. S. Cetin, M. Kasap, S. Ozcelik, and E. Ozbay, "Investigation of AlInN HEMT structures with different AlGaN buffer layers grown on sapphire substrates by MOCVD," Current Applied Physics, vol. 12, pp. 1600-1605, 2012.

[3] I. Saidi, H. Mejri, M. Baira, and H. Maaref, "Electronic and transport properties of AlInN/AIN/GaN high electron mobility transistors," Superlattices and Microstructures, vol. 84, pp. 113-125, 2015.

[4] R. Aggarwal, A. Agrawal, M. Gupta, and R. S. Gupta, "Analytical performance evaluation of AlGaN/GaN metal insulator semiconductor heterostructure field effect transistor and its comparison with conventional HFETs for high power microwave applications," Microwave and Optical Technology Letters, vol. 50, pp. 331-338, 2008.

[5] I. Saidi, Y. Cordier, M. Chmielowska, H. Mejri, and H. Maaref, "Thermal effects in AlGaN/GaN/Si high electron mobility transistors," Solid-State Electronics, vol. 61, pp.1-6, 2011.

[6] J. Kuzmik, M. Tapajna, L. Valik, M. Molnar, D. Donoval, C. Fleury, D. Pogany, G. Strasser, O. Hilt, F. Brunner, and J. Würfl, "Self-Heating in GaN Transistors Designed for High-Power Operation," IEEE Trans. on Electron Devices, vol. 61, pp. 3429-3434, 2014.

[7] S. Guo, X. Gao, D. Gorka, J. W. Chung, H. Wang, T. Palacios, A. Crespo, J. K. Gillespie, K. Chabak, M. Trejo, V. Miller, M. Bellot, G. Via, M. Kossler, H. Smith, and D. Tomich, "AlInN HEMT grown on SiC by metal organic vapor phase epitaxy for millimeter-wave applications," Phys. Status Solidi A, vol. 207, 1348-1352, 2010.

[8] J. S. Xue, J. C. Zhang, K. Zhang, Y. Zhao, L. X. Zhang, X. H. Ma, X. G. Li, F. N. Meng, and Y. Hao, "Fabrication and characterization of InAlN/GaN-based double-channel high electron mobility transistors for electronic applications," J. Appl. Phys., vol. 111, pp. 114513, 2012.

[9] O. Jardel, G. Callet, J. Dufraisse, M. Piazza, N. Sarazin, E. Chartier, M. Oualli, R. Aubry, T. Reveyrand, J. -C. Jacquet, M.-A. Di Forte Poisson, E. Morvan, S. Piotrowicz and S. L. Delage, "Electrical performances of AlInN/GaN HEMTs. A comparison with AlGaN/GaN HEMTs with similar technological process," Int. J. Microwave and Wireless Technol., vol. 3, pp. 301-309, 2011.

[10] Th. Gessmann, J. W. Graff, Y. -L. Li, E. L. Waldron, and E. F. Schubert, "Ohmic contact technology in III nitrides using polarization effects of cap layers," J. Appl. Phys., vol. 92, pp. 3740, 2002.

[11] S. Heikman, S. Keller, Y. Wu, J. S. Speck, S. P. DenBaars, and U. K. Mishra, "Polarization effects in AlGaN/GaN and GaN/AlGaN/GaN heterostructures," J. Appl. Phys., vol. 93, pp. 10114-10118, 2003.

[12] A. Asgaria, M. Kalafia, and L. Faraone, "The effects of GaN capping layer thickness on two-dimensional electron mobility in GaN/AlGaN/GaN heterostructures," Physica E, vol. 25, pp. 431-437, 2005.

[13] J.-T. Zhao, Z.-J. Lin, C. -B. Luan, Y.-J. Lu, Z.-H. Feng and M. Yang, "Effects of GaN cap layer thickness on an AlN/GaN heterostructure," Chin. Phys. B, vol. 23, pp. 127104, 2014.

[14] R. T. Green, I. J. Luxmoore, K. B. Lee, P. A. Houston, F. Ranalli, T. Wang, P. J. Parbrook, M. J. Uren, D. J. Wallis and T. Martin, "Characterization of gate recessed GaN/AlGaN/GaN high electron mobility transistors fabricated using a SiCl4/SF6 dry etch recipe," J. Appl. Phys., vol. 108, pp. 013711, 2010.

[15] H. Li, S. Keller, S. P. Den Baars, and U. K. Mishra "Improved properties of high-Al compositionAlGaN/GaN high electron mobility transistor structures with thin GaN cap layers," Jap. J. Appl. Phys., vol. 53, pp. 095504, 2014.

[16] L. Wang, F. M. Mohammed, B. Ofuonye, and I. Adesida, "Ohmic contacts ton+-GaN capped AlGaN/AlN/GaN high electron mobility transistors," Appl. Phys. Lett., vol. 91, pp. 012113, 2007.

[17] C.-H. Li, Y.-C. Jiang, H.-C. Tsai, Y.-N. Zhong, and Y.-M. Hsin, "Device Characteristics of AlGaN/GaN HEMTs with p-GaN Cap Layer," J. Solid State Sci. Technol., vol. 6, pp. S3125-S3128, 2017.

[18] L. Yang, W. Mao, Q. Yao, Q. Liu, X. Zhang, J. Zhang, and Y. Hao, "Temperature effect on the submicron AlGaN/GaN Gunn diodes for terahertz frequency,” J. Appl. Phys., vol. 109, pp. 024503, 2011.

[19] C. Wood and D. Jena, "Polarization Effects in Semiconductors: From Ab Initio Theory to Device Applications," Springer, New York, 2008.

[20] O. Ambacher, J. Smart, J. R. Shealy, N. G. Weimann, K. Chu, M. Murphy, W. J. Schaff, and L. F. Eastman, "Two-dimensional electron gases induced by spontaneous and piezoelectric polarization charges in $\mathrm{N}$ - and Ga-face AlGaN/GaN heterostructures," J. Appl. Phys., vol. 85, pp. 3222-3233, 1999.

[21] P. Jinrong, S. Jiuxun, and Z. Da, "An Accurate Polynomial Based Analytical Charge Control Model for AlGaN/GaN HEMT,” Physics Semiconductor Devices, vol. 45, pp. 1205-1210, 2011.

[22] O. Ambacher, J. Majewski, C. Miskys, A. Link, M. Hermann, M. Eickhoff, M. Stutzmann, F. Bernardini, V. Fiorentini, V. Tilak, B. Schaff, and L. F. Eastman, "Pyroelectric properties of Al(In)GaN/GaN hetero- and quantum well structures," J. Phys. Condens. Matter., vol. 14, pp. 3399-3434, 2002.

[23] R. Kumar, S. K. Arya, and A. Ahlawat, "Analysis of small-signal parameters of 2-D MODFET with polarization effects for microwave applications," Intern. Journal of VLSICS, vol. 4, pp. 51-61, 2013.

[24] D. Godwinraj, H. Pardeshi , S. K. Pati, N. Mohankumar, C. K. Sarkar, "Polarization based charge density drain current and small-signal model for nano scale AlInGaN/AlN/GaN HEMT devices," Superlattices and Microstructures, vol. 54, pp. 188-203, 2013.

[25] M. Guo, Z. Y. Guo, J. Huang, Y. Liu and S. Y. Yao, "Improvement of the carrier distribution with $\mathrm{GaN} / \mathrm{InGaN} / \mathrm{AlGaN} / \mathrm{InGaN} / \mathrm{GaN}$ composition-graded barrier for InGaN-based blue light emitting diode," Chin. Phys. B, vol. 26, pp. 028502, 2017. 
[26] S. Khandelwal and T. A. Fjeldly, "A physics based compact model of I-V and C-V characteristics in AlGaN/GaN HEMT devices," Solid State Electronics, vol. 76, pp. 60-66, 2012.

[27] S. M. Sze and K. K. Ng, "Physics of Semiconductor Devices," John Wiley and Sons, New York, 2007.

[28] X. Cheng, M. Li, and Y. Wang, "An analytical model for current-voltage characteristics of AlGaN/GaN HEMTs in presence of self-heating effect," Solid-State Electronics, vol. 54, pp. 42-47, 2010.

[29] Z. Wen, Y. Xu, Y. Chen, H. Tao, Ch. Ren, H. Lu, Z. Wang, W. Zheng, B. Zhang, T. Chen, T. Gao and R. Xu, "A Quasi-Physical Compact Large-Signal Model for AlGaN/GaN HEMTs," IEEE Trans. Microwave Theo. Techn., vol. 65, pp. 5113-5122, 2017.

[30] P. Gangwani, R. Kaur, S. Pandey, S. Haldar, M. Gupta, and R. S. Gupta, "Modeling and analysis of fully strained and partially relaxed lattice mismatched AlGaN/GaN HEMT for high temperature applications," Superlattices and Microstructures, vol. 44, pp. 781-793, 2008.

[31] X.-D. Wang, W.-D. Hu, X.-S. Chen, and W. Lu, "The Study of Self-Heating and Hot-Electron Effects for AlGaN/GaN Double-Channel HEMTs,” IEEE Trans. Electron Devices, vol. 59, pp. 1393-1401, 2012.

[32] A. Bellakhdar, A. Telia, L. Semra, and A. Soltani, "The thermal effect on the output conductance in AlGaN/GaN HEMT's," Proc. 24 th Intern. Conf. Microelectronics-ICM 2012-, Dec. 17-20, 2012, Algiers, Algeria.

[33] D. Caughey and R. Thomas, "Carrier Mobilities in Silicon Empirically Related to Doping and Field," Proc. IEEE, vol. 52, pp. 2192-2193, 1967.

[34] Y. Chang, Y. Zhang, and Y. Zhang, "A thermal model for static current characteristics of AlGaN/GaN high electron mobility transistors including self-heating effect," J. Appl. Phys., vol. 99, pp. 044501, 2006.

[35] F. M. Yigletu, S. Khandelwal, T. A. Fjeldly, and B. Iñiguez, "Compact Charge-Based Physical Models for Current and Capacitances in AlGaN/GaN HEMTs,” IEEE Trans. Electron Devices, vol. 60, pp. 3746-3752, 2013.

[36] Y. C. Kong, Y. D. Zheng, C. H. Zhou, S. L. Gu, R. Zhang, P. Han, Y. Shi, and R. L. Jiang, "Two-dimensional electron gas densities in AlGaN/AlN/GaN heterostructures,” Appl. Phys. A, vol. 84, pp. 95-98, 2006.

[37] M. S. Islam, A. Ahad, H. Ahmed, and S. Islam, "Comparative Study Between AlGaN/GaN and AlInN/GaN High Electron Mobility Transistors,” Int. J. Math. Computers in Simul., vol. 11, pp. 106-109, 2017.

[38] W. S. Chen, S. J. Chang, Y. K. Su, R. L. Wang, C. H. Kuo, and S. C. Shei, "AlxGa1-xN/GaN heterostructure field effect transistors with various Al mole fractions in AlGaN barrier," J. Crystal Growth, vol. 275, pp. 398-403, 2005.

\section{BIOGRAPHIES OF AUTHORS}

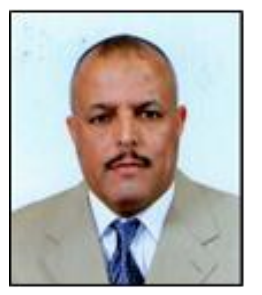

A. Bellakhdar was born in Lahouat, Algeria, in 1965. He received his M.S degree in Microelectronics from Mentouri University of Constantine, Algeria in 2010. He is currently working toward the $\mathrm{PhD}$ degree in Microelectronics in the same university. His current research interests include GaN-based high-electron-mobility-transistor (HEMTs) simulation and III-N compound semiconductor materials and devices modeling. Presently, he is working as an assistant professor and is responsible of the Master Microelectronics in Department of Electronics, Faculty of Technology, Amar Thlidji University, Laghouat, Algeria.

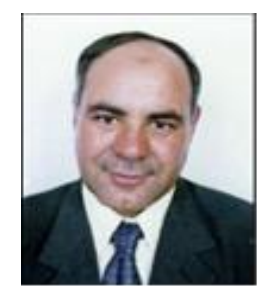

A. Telia was born in Mila, Algeria, in 1961. He received the D.E.S degree in electronics from Constantine University, Algeria, in 1985 and the PhD degree in electronics, from Metz University, France, in 1990. From October 1990, he worked as an Associate Professor and Research Associate at the Department of Electronics Constantine 1 University. From 2007, as a Professor and Research Associate, he is working on wide-bandgap GaN-based HFETs and $\mathrm{ZnO}$ thin films performed using sol gel technique. His research group is carrying modeling studies on different HEMT characteristics and elaborated $\mathrm{ZnO}$ layers for gas sensors.

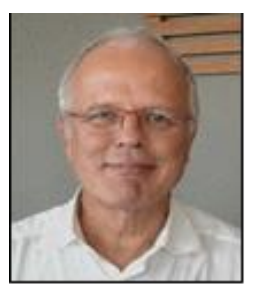

J.-L. Coutaz received the PhD degree in 1981 and the "Docteur d'Etat" degree (habilitation) in 1987, both from University of Grenoble, France. In 1981-1982, he served as a lecturer at the University of Blida, Algeria, under a cooperation scheme. From 1983 to 1993, he was a full-time researcher at the French CNRS, working on guided-wave nonlinear optics. During 1988-1989, he was a Post-Doctoral fellow at the Royal Institute of Technology (KTH), Stockholm, Sweden. In 1993, he became a professor of physics at the University of Savoie, where he has started research activities in ultrafast optoelectronics. He was for several years director of the laboratory LAHC in the same university, and since 2007 he serves as deputy director of the IMEP-LAHC institute. He was an invited professor at KTH Stockholm and at Tohoku University, Sendaï, Japan. His present research activities include terahertz time-domain spectroscopy, electro-optic sampling and ultrafast III-V semiconductor devices. He is the author and co-author of about 600 papers and communications, including two books: THz Optoelectronics EDP Sciences, Paris (2008 in French) and Principles of THz time-domain spectroscopy, Pan Stanford Pub., Singapore (2018). He was the secretary of the French Optical Society (2005-2009). He is the member of the committees of several international conferences, and of the editorial board of the International Journal of Infrared, Millimeter and Terahertz Wave. 